\title{
Optimal Duration of Proton Pump Inhibitor for Healing Artificial Ulcers After Endoscopic Submucosal Dissection for Early Gastric Cancer
}

\author{
Takuji Gotoda
}

Received: 28 November 2011/ Accepted: 1 December 2011/Published online: 25 December 2011

(C) Springer Science+Business Media, LLC 2011

To determine the optimal duration of proton pump inhibitor (PPI) treatment for artificial gastric ulcers caused by endoscopic submucosal dissection (ESD), Lee et al. [1] investigated 333 patients who underwent ESD, utilizing a retrospective analysis $(n=221)$ and prospective randomized validation $(n=112)$. The patients with 8-week PPI administration had significantly greater healing of large ESD defects $(\geq 40 \mathrm{~mm})$ than those with 4-week PPI administration (83.3 vs. $42.6 \%, p<0.01)$. Therefore, they concluded that 8-week courses of PPI administration should be recommended to treat ESD-induced ulcers larger than $40 \mathrm{~mm}$.

Endoscopic resection allows complete histological staging of the cancer, and is superior to biopsy for diagnosing superficial gastrointestinal neoplasia [2]. Endoscopic mucosal resection (EMR) has been widely established as a safe and reasonable procedure for superficial gastrointestinal neoplasia [3, 4]. However, the tumors are frequently removed in fragments [5, 6], and specimens obtained by such piecemeal resection render pathological staging inaccurate [7]. This is a major factor leading to the high risk of recurrence when this technique is used on larger lesions [8].

$\mathrm{T}$ staging using EUS is reportedly accurate in only $80-90 \%$ of cases $[9,10]$. Hence, the final staging can only be done through a formal histological analysis of en bloc

\footnotetext{
T. Gotoda $(\bowtie)$

Department of Gastroenterology and Hepatology,

National Center for Global Health and Medicine,

Tokyo, Japan

e-mail: tgotoda@hosp.ncgm.go.jp

T. Gotoda

Department of Gastroenterology and Hepatology,

Tokyo Medical University, Tokyo, Japan
}

resected material [11]. The ESD technique has been rapidly gaining popularity in Japan and Korea, the countries with the highest incidence of gastric cancer, primarily because of the ability to remove large early gastric cancer (EGC) en bloc [12]. Furthermore, expanded criteria for endoscopic resection have been proposed based on a large study of surgically resected gastric cancers that revealed particular conditions of mucosal cancers with little risk of lymph node metastasis [13]. Recently, many large EGC lesions have been removed by ESD, resulting in large artificial ulcers.

Endoscopic resection is safe, effective, and applicable to a wide variety of clinical situations. However, ESD may cause large and deep defects after the procedure. Green et al. [14] and Berstad [15] have shown that the intragastric $\mathrm{pH}$ should be 6.0 or above to allow platelet aggregation and prevent disaggregation. PPIs and histamine $\mathrm{H} 2$ receptor antagonists (H2RAs) are generally administered for the treatment of ESD-related ulcers. In standard EMR, artificial ulcers were thought to heal faster and to recur less often than peptic ulcers [16]. Lee et al. [17] reported that at least 4 weeks of PPI administration was required to close even small ulcers after EMR. Yamaguchi et al. [18] found no significant difference between the effect of PPI and that of H2RA for small ulcers caused by ESD and EMR.

In contrast, Ye et al. [19] reported that active ulcers remained at a higher incidence after 4 weeks of H2RA treatment than after PPI administration in ESD-/EMRinduced ulcers with an approximate size of $10 \mathrm{~mm}$. Uedo et al. [20] reported that 8 weeks of PPI administration was sufficient to prevent re-bleeding from ESD defects smaller than $20 \mathrm{~mm}$. Oh et al. [21] reported that the size of the initial defect affects the rate of ulcer healing at 4 weeks of PPI administration post-ESD. Kakushima et al. [22] reported that 4 weeks of PPI administration was not 
sufficient, and 8 weeks of administration was required to obtain satisfactory results for larger ulcers after ESD.

Very recently, Imaeda et al. [23] assessed the effects of PPI and H2RA for the prevention of bleeding and the promotion of ulcer healing after ESD, and compared the cost-effectiveness of these two drugs. In this study, although two of the 62 patients $(3.2 \%)$ in the PPI group and three of the 61 patients $(4.9 \%)$ in the H2RA group showed bleeding after ESD, there was no significant difference between the two treatment groups. The ulcer-healing rate was $93.5 \%$ (58/62) in the PPI group and 93.4\% (57/61) in the H2RA group. The total cost of treatment with the antisecretory agent from the day of the ESD to day 56 after the ESD was 13,212 yen for PPI and 5,841 yen for H2RA. The authors concluded that H2RA appears to have a high cost effectiveness in the prevention of bleeding and in the promotion of ulcer healing after ESD for superficial gastric neoplasia.

The optimal dose of PPI for the treatment of artificial ulcers after ESD has not yet been established. Gastric peptic ulcer healing rates using half-dose PPI were reported to be significantly better than those seen when using a standard dose of H2RA [24]. However, there had been no study using half-dose PPI for treating artificial ulcers after ESD. Kawano et al. [25] evaluated the possibility of reducing the dose of PPI from $30 \mathrm{mg}$ (standard-dose) to $15 \mathrm{mg}$ (half dose), and examined ulcer healing, prevention of bleeding, and quality of life. In this study, 91 patients with gastric mucosal neoplasms were enrolled. All patients who underwent ESD were given a standard dose of a PPI daily during the first week, after which they were randomly assigned to either the standard-dose or half-dose group. The stage of ulcers, ulcer reduction ratios, and scores on the Gastrointestinal Symptom Rating Scale did not differ at 28 and 56 days between the groups. The costs of PPI for the half-dose group and standard-dose group were 7,326.5 and 11,698.4 yen, respectively. The authors concluded that a reduced dose of PPI after 1 week of ESD was equivalent in treatment performance to the standard dose regimen, and was less expensive.

Kato et al. [26] recently indicated that combination therapy of a PPI with rebamipide, a mucosa-protective antiulcer drug, was more effective than the PPI alone for treating ulcers larger than $20 \mathrm{~mm}$ within 4 weeks after ESD. Fujiwara et al. [27] also reported that combination treatment with a PPI plus rebamipide improved healing rates at 8 weeks for patients with ESD-derived artificial ulcers, and appeared to be particularly effective for patients with severe atrophic gastritis. These studies demonstrate the efficacy of a combination of PPI with rebamipide in comparison to PPI alone for early healing of large-sized defects after ESD. These effects may mitigate the limitation of single drug PPI therapy in terms of both the ulcer size and the drug administration period after ESD. Kakushima et al. [28] showed that the infection status of
Helicobacter pylori and the extent of gastric atrophy do not affect ulcer healing when treating with a combination therapy of sucralfate and PPI at 8 weeks after ESD.

There is no doubt about the significant advantages of ESD as a minimally invasive but curative treatment for EGC. However, the sufficient doses of PPI or H2RA, including combination therapies, for ESD-induced artificial ulcers are not yet established. Eight-week PPI (standard dose) administration is an effective treatment that should be widely applied for complete, rapid, and definitive healing of large artificial defects caused by ESD.

As for future investigations, we should clarify whether the eradication of Helicobacter pylori should be undertaken before ESD to aid in the healing of artificial ulcers and/or prevent delayed bleeding. Lee et al. have also excluded patients currently using aspirin and/or anticoagulant agents. Elderly patients have a higher frequency of using aspirin and/or anticoagulant drugs, however, and the increased chance of delayed bleeding from ESD-related artificial ulcers these drugs can create might be more detrimental than the beneficial effects these drugs can provide in elderly patients. We should determine the proper timing of PPI drug withdrawal, and the proper dose and optimal duration of PPI (or H2RA) treatment in this era of an aging society.

Conflict of interest Author has no financial relationships relevant to this publication.

\section{References}

1. Lee S-H, Lee CK, Chung I-K, et al. Optimal duration of proton pump inhibitor in the treatment of endoscopic submucosal dissection-induced ulcers: a retrospective analysis and prospective validation study. Dig Dis Sci. (Epub ahead of print). doi: 10.1007/s10620-011-1941-2.

2. Hull MJ, Mino-Kenudson M, Nishioka NS, et al. Endoscopic mucosal resection: an improved diagnostic procedure for early gastroesophageal epithelial neoplasms. Am J Surg Pathol. 2006;30:114-118.

3. Rembacken BJ, Gotoda T, Fujii T, et al. Endoscopic mucosal resection. Endoscopy. 2001;33:709-718.

4. Soetikno RM, Gotoda T, Nakanishi Y, et al. Endoscopic mucosal resection. Gastrointest Endosc. 2003;57:567-579.

5. Inoue $\mathrm{H}$, Takeshita $\mathrm{K}$, Hori $\mathrm{H}$, et al. Endoscopic mucosal resection with a cap-fitted panendoscope for esophagus, stomach, and colon mucosal lesions. Gastrointest Endosc. 1993;39:58-62.

6. Akiyama M, Ota M, Nakajima $\mathrm{H}$, et al. Endoscopic mucosal resection of gastric neoplasms using a ligating device. Gastrointest Endosc. 1997;45:182-186.

7. Eguchi T, Gotoda T, Oda I, et al. Is endoscopic one-piece mucosal resection essential for early gastric cancer? Dig Endosc. 2003; 15:113-116.

8. Tanabe S, Koizumi W, Mitomi H, et al. Clinical outcome of endoscopic aspiration mucosectomy for early stage gastric cancer. Gastrointest Endosc. 2002;56:708-713. 
9. Yanai H, Noguchi T, Mizumachi S, et al. A blind comparison of the effectiveness of endoscopic ultrasonography and endoscopy in staging early gastric cancer. Gut. 1999;44:361-365.

10. Ohashi S, Segawa K, Okamura S, et al. The utility of endoscopic ultrasonography and endoscopy in the endoscopic mucosal resection of early gastric cancer. Gut. 1999;45:599-604.

11. Oda I, Gotoda T, Sasako M, et al. Treatment strategy after noncurative endoscopic resection of early gastric cancer. Br J Surg. 2008;95:1495-1500.

12. Gotoda T, Yamamoto H, Soetikno R. Endoscopic submucosal dissection for early gastric cancer. J Gastroenterol. 2006;41: 929-942.

13. Gotoda T, Yanagisawa A, Sasako M, et al. Incidence of lymph node metastasis from early gastric cancer: estimation with a large number of cases at two large centers. Gastric Cancer. 2000; 3:219-225.

14. Green FW, Kaplan MM, Curtis LE, et al. Effect of acid and pepsin on blood coagulation and platelet aggregation. A possible contributor to prolonged gastroduodenal mucosal hemorrhage. Gastroenterology. 1978;74:38-43.

15. Berstad A. Management of acute upper gastrointestinal bleeding. Scand J Gastroenterol. 1982;75:103-108.

16. Hashimoto T, Adachi K. Changes in gastric mucosal blood flow during healing of EMR-induced ulcer. Dig Endosc. 1997;9: 127-131.

17. Lee SY, Kim JJ, Lee JH, et al. Healing rate of EMR induced ulcer in relation to the duration of treatment with omeprazole. Gastrointest Endosc. 2004;60:213-217.

18. Yamaguchi Y, Katsumi N, Tauchi M, et al. A prospective randomized trial of either famotidine or omeprazole for the prevention of bleeding after endoscopic mucosal resection and the healing of endoscopic mucosal resection-induced ulceration. Aliment Pharmacol Ther. 2005;21:111-115.

19. Ye BD, Cheon JH, Choi KD, et al. Omeprazole may be superior to famotidine in the management of iatrogenic ulcer after endoscopic mucosal resection: a prospective randomized controlled trial. Aliment Pharmacol Ther. 2006;24:837-843.
20. Uedo N, Takeuchi Y, Yamada T, et al. Effect of a proton pump inhibitor or an H2-receptor antagonist on prevention of bleeding from ulcer after endoscopic submucosal dissection of early gastric cancer: a prospective randomized controlled trial. Am J Gastroenterol. 2007;102:1610-1616.

21. Oh TH, Jung HY, Choi KD, et al. Degree of healing and healingassociated factors of endoscopic submucosal dissection-induced ulcers after pantoprazole therapy for 4 weeks. Dig Dis Sci. 2009;54:1494-1499.

22. Kakushima N, Yahagi N, Fujishiro M, et al. The healing of gastric ulcers after endoscopic submucosal dissection. Dig Endosc. 2004;16:327-331.

23. Imaeda H, Hosoe N, Suzuki H, et al. Effect of lansoprazole versus roxatidine on prevention of bleeding and promotion of ulcer healing after endoscopic submucosal dissection for superficial gastric neoplasia. J Gastroenterol. Epub. 07/30/2011.

24. Campbell DR, Haber MM, Sheldon E, et al. Effect of H. pylori status on gastric ulcer healing in patients continuing nonsteroidal anti-inflammatory therapy and receiving treatment with lansoprazole or ranitidine. Am J Gastroenterol. 2002;97:2208-2214.

25. Kawano S, Okada H, Kawahara Y, et al. Proton pump inhibitor dose-related healing rate of artificial ulcers after endoscopic submucosal dissection: a prospective randomized controlled trial. Digestion. 2011;84:46-53.

26. Kato T, Araki H, Onogi F, et al. Clinical trial: rebamipide promotes gastric ulcer healing by proton pump inhibitor after endoscopic submucosal dissection-a randomized controlled study. J Gastroenterol. 2010;45:285-290.

27. Fujiwara S, Morita Y, Toyonaga T, et al. A randomized controlled trial of rebamipide plus rabeprazole for the healing of artificial ulcers after endoscopic submucosal dissection. $J$ Gastroenterol. 2011;46:595-602.

28. Kakushima N, Fujishiro M, Yahagi N, et al. Helicobacter pylori status and the extent of gastric atrophy do not affect ulcer healing after endoscopic submucosal dissection. J Gastroenterol Hepatol. 2006;21:1586-1589. 